\title{
Designing and using robots for performing inspections in potentially explosive atmospheres
}

\author{
Cosmin Colda ${ }^{*}$, and Sorin Burian \\ National Institute for Research and Development in Mine Safety and Protection to Explosion - \\ INSEMEX, 32-34 G-ral Vasile Milea street, 332047, Petrosani, Hunedoara county, Romania
}

\begin{abstract}
Directive 2014/34/EU ATEx regulates the placement on the European market of equipment and technical installations for use in potentially explosive atmospheres. The current article has as purpose to present the manner of choosing types of protection for designing robots intended to be used for performing inspections in atmospheres with explosion hazard. The safety of workers has led to the development of technologies required for simplifying and safe performance of inspections in areas with explosion hazard.
\end{abstract}

\section{Introduction}

Electrical installations operating in hazardous atmospheres have characteristics specially designed in order to make them suitable for operation in such atmospheres. It is essential, for safety reasons in these areas, that, during the lifetime of these installations, the integrity of such special features to be preserved $[1,2]$; therefore, they require an initial inspection and either:

a) subsequent regular periodic inspections, or

b) supervision by qualified personnel

in accordance with EN 60079-17 and, when necessary, also maintenance [3].

Installations in which flammable materials are handled or stored must be designed, operated and maintained so that all releases of flammable materials, and consequently the extent of hazardous areas, are kept to a minimum in terms of frequency, duration and quantity, whether the operation is normal or not $[4,5]$.

It is important to check those parts of the production equipment and systems from which the release of the flammable substance may occur and to consider changing their design considering the reduction in the probability and frequency of occurrence of such flammable substances, of the quantity and level of releases.

The probability of the presence of a gaseous explosive atmosphere depends mainly on the degree of release and ventilation. This is identified as the hazardous area. The hazardous areas are split into: zone 0 , zone 1 , zone 2 and non-dangerous zone [6-8].

\footnotetext{
* Corresponding author: cosmin.colda@insemex.ro
} 
The extent of the area depends mainly on the physical and chemical parameters of the flammable material and on the production process.

The novelty of the paper is represented by presentation of the development of modular robots intended for use bot in maintenance and repair activities, as well as in interventions in areas with fire and explosion hazard, where may occur toxic and/or explosive atmospheres.

\section{Aspects and requirements regarding the inspection of installations}

Before the installation or equipment is put into service, it must undergo an initial inspection.

To ensure that the installations are maintained in a satisfactory condition for continuous use in a hazardous area, there must be carried out:

- regular periodical inspections, or

- continuous supervision by qualified personnel and, if necessary, maintenance.

Regular periodic inspections require personnel who:

- have knowledge about the classification of areas / EPL and sufficient technical knowledge to understand their implications on the considered location;

- have technical knowledge and understand the practical and theoretical requirements for electrical equipment and installations used in hazardous areas;

- understand the requirements of visual, rigorous and detailed inspections in conjunction with the equipment and installations installed.

If an installation is regularly inspected during the normal work program, the qualified personnel must:

- be aware of the implications of the process and the environment on the deterioration of the specific equipment in the installation, and

- conduct visual and / or rigorous inspections as part of their normal work schedule, as well as detailed inspections.

In this case it is possible to opt out of regular periodic inspections and use the frequent presence of qualified personnel to ensure the continuous integrity of the equipment.

The application of continuous supervision by qualified personnel does not eliminate the need for initial inspection and sampling.

Continuous surveillance cannot be applied to electrical equipment for which this type of surveillance cannot be provided (for example in the case of mobile equipment).

The objective of continuous surveillance is to allow the early detection of defects and the necessary repairs. It makes use of existing qualified personnel who oversee the installation during their normal operation (for example, assembly work, modification, inspection, maintenance work, fault finding, cleaning work, command operations, switching operations, switching on and off terminals, working on terminals, assembly and adjustment, functional tests, measurements) and that use their qualification to detect defects and changes from an early stage [2].

\section{Types of explosion protection with which robots can be designed}

The use of electricity in potentially explosive atmospheres has many peculiarities, for which the problems raised by the design, construction and operation of electrical equipment and installations present many difficulties, their approach requiring special attention in 
considering the multiple technical and economic aspects of labor safety. Thus, special attention is paid to the aspects regarding the construction and marking of electrical equipment, cable inputs and Ex components, intended for use in explosive atmospheres generated by gases, vapors or flammable mists.

Taking into account the constructive and functional aspects of the electrical equipment, types of protection [9-14] for the different electrical equipment have been developed and are presented in Table 1.

Table 1. Suitable Ex types of protection identified for robotic components.

\begin{tabular}{|c|c|l|}
\hline \multicolumn{2}{|c|}{ Type of protection } & \multirow{2}{*}{ Equipment type - Operational role } \\
\cline { 1 - 2 } Symbol & Name & \\
\cline { 1 - 2 } Ex m & Encapsulation & parts of circuits; small components etc. \\
\hline Ex p & $\begin{array}{c}\text { Pressurized } \\
\text { enclosures }\end{array}$ & $\begin{array}{l}\text { control panels; analysers; rotary machines; } \\
\text { electrical appliances etc. }\end{array}$ \\
\hline Ex e & Increased safety & $\begin{array}{l}\text { rotary machines; lighting objects; terminal / } \\
\text { branch boxes etc. }\end{array}$ \\
\hline Ex n & Non-sparking & $\begin{array}{l}\text { rotary machines; lighting objects; terminal / } \\
\text { branch boxes etc. }\end{array}$ \\
\hline Ex d & $\begin{array}{c}\text { Flameproof } \\
\text { enclosures }\end{array}$ & $\begin{array}{l}\text { rotary machines; lighting objects; terminal / } \\
\text { branch boxes; on-off switches; electrical } \\
\text { appliances etc. }\end{array}$ \\
\hline Ex i & Intrinsic safety & $\begin{array}{l}\text { monitoring - control - signalling system; } \\
\text { generally low current equipment. }\end{array}$ \\
\hline
\end{tabular}

\section{Development of mobile robots for inspection activities in Ex atmospheres}

The need to carry out inspections in areas with danger of explosion that are difficult to access or dangerous to humans has led to the development of mobile robots for performing such tasks [15].

Performing inspections through the use of mobile robots must take place when the human factor cannot participate in such an activity due to the high explosion risks in the respective area [16].

In order to satisfy a large part of the industries in which there are Ex-classified areas, from the point of view of explosion protection the robots must be:

- Independent: they are self- charging and require no human intervention

- Reliability: they are designed to operate for months, or even years, without maintenance

- Ruggedness: they can operate in a wide range of climates.

The mobile robots should have a compact structure, small size, and high stability and mobility. Its dimensions cannot exclude the possibility of transport through a fire-dam tube in an anti-explosion dam. The device should also have as low weight as possible in order to enable manual. Uncomplicated control shall be performed remotely-from the rescue base. Instrumentation (sensors, cameras) should be protected from possible damage.

The main obstacles and hindrances which the robot can encounter during the inspection and which should be dealt with include:

- $\quad$ significant reduction or total lack of visibility,

- $\quad$ high temperature (up to 60 degrees Celsius) and humidity (up to $100 \%$ ),

- difficult terrain

- numerous obstacles 
- technological obstacles, tubes, pipes, cables, ventilation fans, and lutes.

The main robot chassis contains the motion subsystem, the main control system, the communication subsystem and power supply.

The main control system is responsible for motion control, management of communication between all subsystems, autonomous behaviour, 3D map building, collision prevention, etc. This requires high computational power while keeping low power consumption, it was thus decided to use the Industrial PC.

The control system software is based on the Robotic Operating System (ROS). The system is modularly divided into several parts (ROS nodes) that are responsible for individual logical tasks (motion, sensors, autonomy, communication, 3D map building, etc.).

A very important part of the mobile robot is the sensory head located on the top of the tiltable sensory arm. The sensory head contains cameras (for stereoscopic view, wide field of view, rear view and thermal camera), LED lighting, various gas sensors, and an inertial measurement unit.

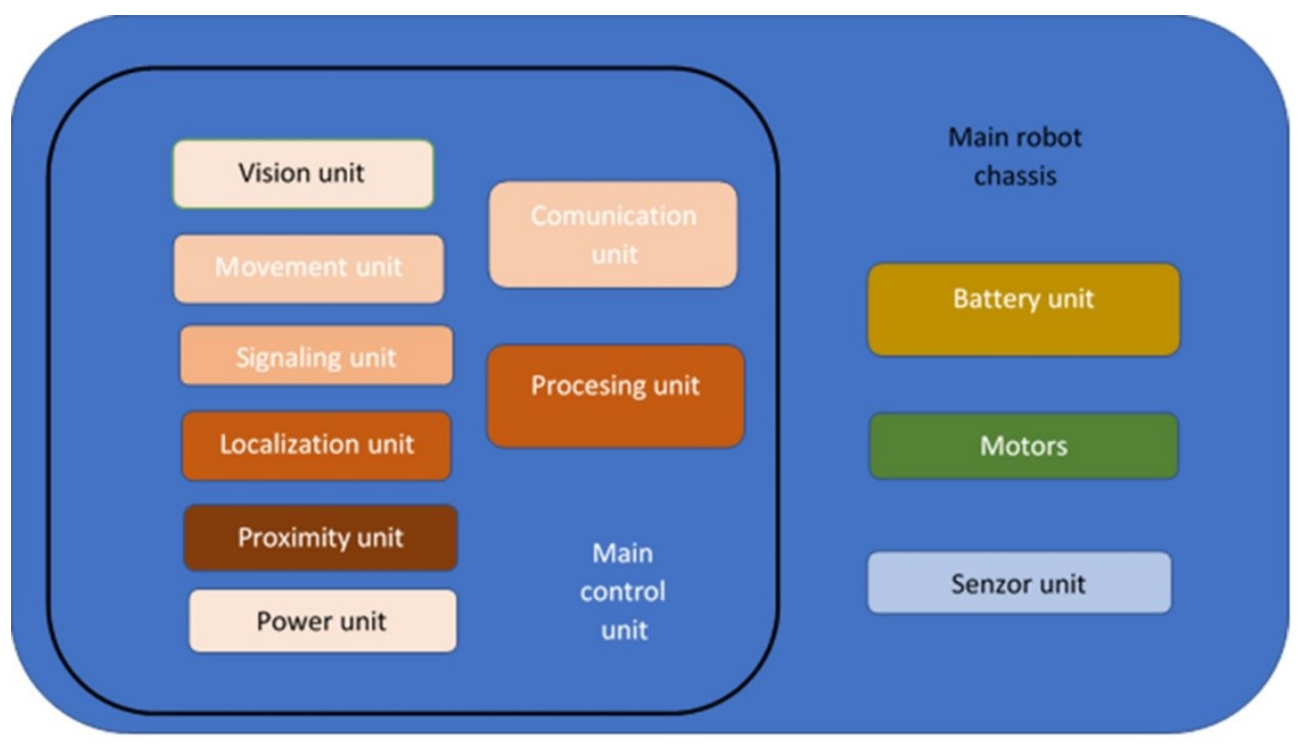

Fig. 1. Robotic operating system diagram.

\section{Conclusions and proposals}

The safety of the workers is of particular importance in the execution of inspections in areas with danger of explosion, which is why it is desired to implement these operations (visual inspections, monitoring of explosive atmospheres and visual defects) by mobile robots.

Due to the high accuracy sensors the robots can measure and monitor the formation of explosive atmospheres in Ex classified areas.

The ones presented in this paper reside in the proposal of future studies for the implementation of the different techniques and methods of monitoring the classified areas Ex, in the component of mobile robots.

It is proposed to study and even develop a prototype of robot accessible to different industrial platforms (hard to reach areas, different types of atmosphere, different climates, etc.). 


\section{References}

1. Directive 2014/34/EU, (2014).

2. D. Pasculescu, L. Pana, V. M. Pasculescu, F. Deliu, Mining of Mineral Deposits, 13 (2), 1-16, (2019).

3. Standard EN 60079-17, (2013).

4. V. M. Pasculescu, N. I. Vlasin, E. Ghicioi, G. D. Florea, M.C. Suvar, Environ Eng Manag J, 18 (4), 889-900, (2019).

5. M. Magyari, S. Burian, L. Moldovan, D. Fotau, C. Colda, Proceedings of the 15th International Multidisciplinary Scientific Geoconference SGEM 2015, 835-842, (2015).

6. Standard EN 60079-0, (2017).

7. V. M. Pasculescu, N. I. Vlasin, M. C. Suvar, C. Lupu, Environ Eng Manag J, 16 (6), 1323-1330 (2017).

8. V. M. Pasculescu, D. G. Pricop, M. S. Morar, V. A. Florea, Proceedings of the 15th International Multidisciplinary Scientific GeoConference SGEM 2015, 1 (2), 291-298, (2015).

9. Standard EN 60079-1, (2014).

10. Standard EN 60079-2, (2014).

11. Standard EN 60079-7, (2015).

12. Standard EN 60079-11, (2011).

13. Standard EN 60079-15, (2017).

14. Standard EN 60079-18, (2014).

15. S. Kohlbrecher, O. von Stryk, Kunstliche Intelligenz, 30 (3-4), 311-314, (2016).

16. P. Novak, T. Kot, J. Babjak, Z. Konecny, W. Moczulski, A.R. Lopez, Applied Sciences Basel, 8 (11), 2300, (2018). 